
www.tms.org/Meetings.

\section{Other Meetings of Note}

Materials in Nuclear

Energy Systems

(MiNES 2021)

September 19-23, 2021

Pittsburgh, Pennsylvania, USA

\section{Congress on Safety \\ in Engineering and \\ Industry 2021 \\ (Safety Congress 2021) \\ November 1-3, 2021 \\ Fort Worth, Texas, USA}

TMS Materials Innovation

Briefing: Focus on

Pittsburgh

November 10, 2021

Cranberry Township,

Pennsylvania, USA

\section{2nd World Congress on \\ High Entropy Alloys \\ (HEA 2021)}

December 5-8, 2021

Charlotte, North Carolina, USA

TMS 2022 Annual

Meeting \& Exhibition

(TMS2022)

February 27-

March 3, 2022

Anaheim, California, USA

\section{Offshore Technology}

Conference

(OTC Asia 2022)

March 22-25, 2022

Kuala Lumpur, Malaysia

Additive Manufacturing

Benchmarks

August 15-18, 2022

Bethesda, Maryland, USA

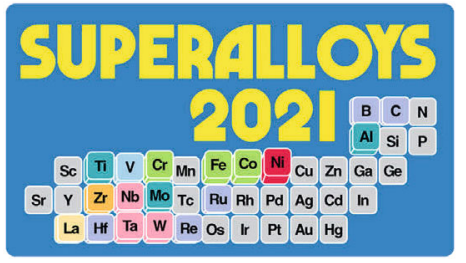

September 12-16, 2021

Virtual Event

Register Now

www.tms.org/Superalloys2021

- The 14th International Symposium on Superalloys (Superalloys 2021) aims to highlight technologies for lifecycle improvement of superalloys. In addition to traditional focus areas, the symposium invites papers from academia, supply chain, and product-user members of the superalloy community that highlight technologies that contribute to improving manufacturability, affordability, life prediction, and performance of superalloys.

- As the latest installment of one the most established and impactful conferences series on superalloys, Superalloys 2021 will showcase some of the leading names in the field as presenters, with papers carefully and stringently curated to ensure the highest quality programming.

\section{MS \\ October 17-21, 2021 \\ Columbus, Ohio, USA}

Registration Now Open!

www.matscitech.org/MST21

- Materials Science and Technology (MS\&T) is three meetings in one: the TMS Fall Meeting, the American Ceramic Society's 123rd Annual Meeting, and the Association for Iron \& Steel Technology's Steel Properties \& Applications event.

- More than 25 symposia are planned as part of the TMS Fall Meeting to be held at MS\&T21. Visit the website for updates on registration.

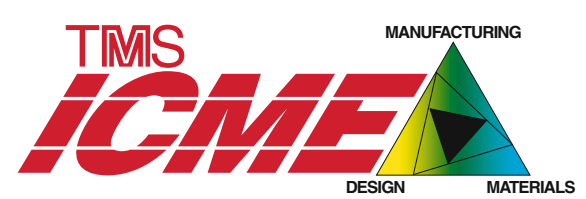

November 14-18, 2021

Lake Tahoe, Nevada, USA

Discount Registration Deadline: October 1, 2021

www.tms.org/ICME2021

- The 6th World Congress on Integrated Computational Materials Engineering (ICME 2021) convenes leading researchers and practitioners to share the latest knowledge and advances in the discipline. This congress is the recognized hub of interaction among software developers and process engineers along the entire production chain, as well as for materials scientists and engineers developing new materials.

- The plenary speakers include Bita Ghaffari, Ford Motor Company; Louis Hector, GM Global Technical Center; Andrea Rovinelli, Argonne National Laboratory; and Kandler Smith, National Renewable Energy Laboratory.

TIMS

First World Congress on

$\triangle$ RTIFICIAL NTELLIGENCE

ATERIALS \& MANUFACTURING 2022

April 3-6, 2022

Pittsburgh, Pennsylvania, USA

Submit an Abstract by

September 3, 2021

www.tms.org/AIM2022

- The TMS World Congress on

Artificial Intelligence in Materials and

Manufacturing (AIM 2022) is the first event of its kind to focus on the role of artificial intelligence in materials science and engineering and related manufacturing processes.

- The goal of AIM 2022 is to convene stakeholders from academia, industry, and government to address key issues and identify future pathways.

- Share your work today! Visit the website to submit your abstract. 